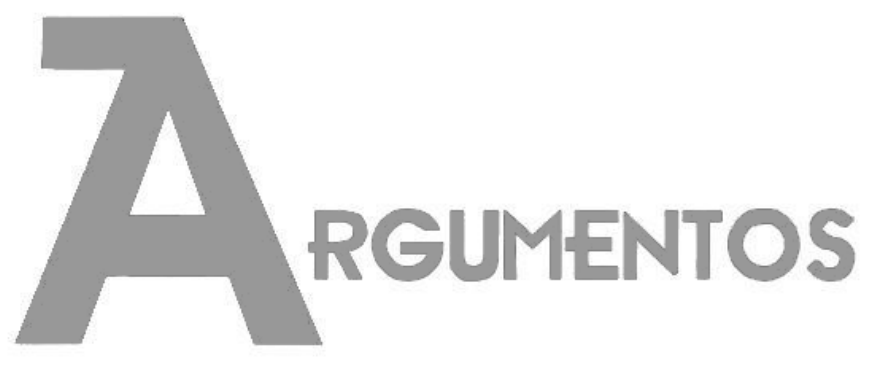

Vol. 18, n. 1, jan./jun. 2021 ISSN: 2527-2551 (online)

\title{
Quando nenhum lugar é seguro: a violência contra corpos negros em Alagoas
}

Emerson do Nascimento ${ }^{1}$

Luciana Santana ${ }^{2}$

Recebido em: 22/01/2020

Aprovado em: 08/02/2020

Resumo: A violência, em suas mais variadas facetas, constitui-se em um fenômeno histórico, social e político e, no Brasil, o fenômeno tem guardado uma profunda conexão com um processo de naturalização da dor e sofrimento, especialmente contra pessoas negras. $O$ artigo analisa os significados da violência racializada, com atenção para as responsabilidades estatais e da sociedade civil para o seu enfrentamento. Discute os desdobramentos da relação entre segurança pública e negritude no Brasil, bem como os limites da extensão dessa violência sobre a população negra no estado de Alagoas. A despeito da extensão que o tema da violência impõe ao observador, a análise priorizou o tratamento dos dados referentes à violência letal. 0 argumento central é o de a violência pode ser entendida como um trauma que, em se tratando do caso alagoano, tem cimentado na psiquê dos membros da sociedade e das próprias instituições de segurança do estado, a normalização dessa violência e das injustiças outras que o fenômeno impõe.

Palavras-chave: Violência, Negros, Alagoas.

\section{Cuando ningún lugar es seguro: violencia contra cuerpos negros en Alagoas}

Resumen: La violencia, en sus más variadas facetas, constituye un fenómeno histórico, social y político y, en Brasil, el fenómeno ha mantenido una profunda conexión con un proceso de naturalización del dolor y el sufrimiento, especialmente contra los negros. El artículo analiza los significados de la violencia racial, prestando atención a las responsabilidades del Estado y la sociedad civil para abordarla. Se discuten las consecuencias de la relación entre seguridad pública y negritud en Brasil, así como los límites del alcance de esta violencia sobre la población negra en el estado de Alagoas. A pesar de la extensión que el tema de la violencia impone al observador, el análisis priorizó el tratamiento de los datos relacionados con la violencia letal. El

\footnotetext{
${ }^{1}$ Cientista político. Professor do Programa de Pós-Graduação em Sociologia e do Instituto de Ciências Sociais da Universidade Federal de Alagoas (UFAL), Brasil. E-mail: emersondonascimento@yahoo.com.br. ORCID: http://orcid.org/0000-0002-5983-5964.

${ }^{2}$ Cientista política. Professora do Instituto de Ciências Sociais da Universidade Federal de Alagoas (UFAL), Brasil. E-mail: luhist@gmail.com ORCID: http://orcid.org/0000-0002-0203-1594 .
} 
argumento central es que la violencia puede entenderse como un trauma que, en el caso de Alagoas, ha cimentado en la psique de los miembros de la sociedad y de las propias instituciones de seguridad del Estado, la normalización de esta violencia e injusticias distintas de las impone el fenómeno.

Palabras-clave: Violencia, Negros, Alagoas.

\title{
When no place is safe: violence against black bodies in Alagoas
}

\begin{abstract}
Violence, in its most varied facets, constitutes a historical, social and political phenomenon and, in Brazil, the phenomenon has kept a deep connection with a process of naturalization of pain and suffering, especially against black people. The article analyzes the meanings of racialized violence, paying attention to state and civil society responsibilities for addressing it. It discusses the consequences of the relationship between public security and blackness in Brazil, as well as the limits of the extent of this violence on the black population in the state of Alagoas. Despite the extent that the theme of violence imposes on the observer, the analysis prioritized the treatment of data related to lethal violence. The central argument is that violence can be understood as a trauma that, in the case of Alagoas, has cemented in the psyche of members of society and the state security institutions themselves, the normalization of this violence and injustices other than the phenomenon imposes.
\end{abstract}

Keywords: Violence, black, Alagoas.

\section{Introdução}

A violência, em suas mais variadas facetas, constitui-se num fenômeno histórico, social e político, há muito conhecido no Brasil. Historicamente, este fenômeno tem guardado uma relação perversa de naturalização da violência perpetrada contra pessoas negras. É sobre essa conexão e sobre as dimensões desse processo de naturalização da violência junto à população negra de que trata este artigo, especialmente, os crimes violentos letais intencionais cujos principais alvos por todo o país são os jovens negros.

O texto está dividido em quatro seções. Na primeira seção apresentaremos uma discussão sobre os significados da violência racializada, com atenção para as responsabilidades estatais e da sociedade civil no seu enfrentamento. Na sequência, discutiremos os desdobramentos da relação entre segurança pública e negritude no Brasil para, depois, na terceira seção, apontaremos para os limites da extensão dessa violência sobre a população de cor do estado de Alagoas. Na última seção, apresentamos nossas considerações finais e as conclusões preliminares deste estudo.

Priorizaremos na nossa análise, à despeito da extensão que o tema da violência impõe ao observador, o tratamento dos dados referentes à violência letal como principal meio de mensuração dessa violência, como já citado anteriormente. 
Dossiê | Quando nenhum lugar é seguro: a violência contra corpos negros em Alagoas (NASCIMENTO, Emerson do; SANTANA, Luana)

Argumentamos que a violência precisa ser pensada enquanto um fenômeno-trauma, que não se restringe no tempo, no espaço e sobre uma única geração de indivíduos. Em se tratando do caso alagoano, em especial, argumentamos que os ciclos históricos de violência a que essa população sempre esteve submetida têm cimentado na psiquê dos membros da sociedade local e das próprias instituições de segurança do estado, uma espécie de normalização dessa violência e de todas as outras injustiças que o fenômeno enseja sobre a população negra - transformando hoje, Alagoas, no estado menos seguro para um indivíduo de cor.

\section{A violência contra o corpo negro}

A violência racializada não é uma anomalia. Antes de mais nada, ela precisa ser reconhecida como parte constitutiva da identidade social e política brasileira. Sua negação é um paço firme em direção à preservação sistêmica do racismo contra corpos negros e contra ainda um conjunto de outros preconceitos e formas de terror que se agravam pela interseccionalidade do racismo - tratamos aqui da mulher negra, do LBGTQ negro, do idoso, da criança negros e, especialmente, dos jovens periféricos negros.

Há séculos, no nosso país, corpos negros são marcados para a morte. Da escravidão à vulnerabilidade que vitima hoje jovens negros nas periferias das principais cidades brasileiras, há muito de continuísmo em relação à preservação desse modelo histórico de exploração e extermínio dessa população, mas há também muito de novidade (CHOLHOUB, 2011; GORENDER, 2016). Aqui, citamos o argumento que folcloriza a participação negra na formação nacional, mas se omite quanto seu genocídio e se silencia quanto a dor e ao sofrimento de corpos negros (RIBEIRO JÚNIOR, 2010).

Exatamente em função do seu caráter sistêmico, a violência racializada não pode e não deve se limitar à teoria, pois a violência que continua a limitar pessoas de cor apoia-se sobre práticas mais e menos sutis que vão desde a negação, individual ou institucional da categoria raça, até a operação de ações e políticas que reforçam o tratamento da população negra como cidadãos de segunda classe ou até mesmo subhumanos, o que reforça a descartabilidade dos corpos e das personas destes sujeitos (VARGAS, 2010). 
Dossiê | Quando nenhum lugar é seguro: a violência contra corpos negros em Alagoas (NASCIMENTO, Emerson do; SANTANA, Luana)

Não por acaso, talvez hoje, nenhuma outra pauta social e humanística da agenda política nacional carece antes, antes de mais nada, de reconhecimento, como a questão da violência racializada. O reconhecimento destas práticas sistêmicas é o primeiro passo do processo. Uma política e uma educação antirracista deve partir não só de uma desnaturalização do racismo, mas do seu entendimento a partir de uma dimensão estrutural que nos obriga a pensar o racismo como processo histórico e processo político.

Consciência ética, vontade política e coragem são ingredientes importantes para alavancar esse debate no plano nacional hoje. Contudo, o fortalecimento de uma onda política e social conservadora a partir de 2018 , que se corporificou no sucesso eleitoral do candidato Jair Bolsonaro tem potencializado não somente os discursos racistas e intolerantes em relação às desigualdades étnicas e raciais no país, mas estimulado até mesmo afirmativas de caráter negacionistas, reverberadas por figuras políticas chaves desde então.

Ainda durante a campanha eleitoral, e levando em conta mesmo o histórico do candidato e suas afirmativas ao longo da sua vida pública, é possível se reproduzir um farto corolário de afirmativas que vão desde a romantização da escravidão até a sua plena negação ou rejeição (NASCIMENTO, 2016). Com isso, não se pretende afirmar que a eleição de Jair Bolsonaro, como que por um passe de mágicas, fez do Brasil um país racista. A veiculação pública destas afirmativas parece ter potencializado a negação de princípios elementares de civilidade que acreditávamos já tê-los, ao menos, conquistado. Estávamos enganados.

A violência é um fenômeno que não se limita ou se restringe à interação física ou ao corpo físico do indivíduo. A violência pode e deve ser medida para todo o ser e também não pode, nem deve, se limitar a ser observada ou compreendida como um ponto isolado no tempo. A violência tem ramificações e precisa ser compreendida como trauma, que cria problemas adicionais ao longo de uma vida e, por isso mesmo, precisa ser cuidadosamente vigiada, haja vista que, como um trauma, quando não é tratado ou remediado, também pode ser transmitido geracionalmente.

A transmissão geracional da transmissão traumática das experiências de violência é capaz de moldar os descendentes daqueles que foram violentados psicologicamente e fisicamente. É nesse sentido que se pode entender que a violência 
Dossiê | Quando nenhum lugar é seguro: a violência contra corpos negros em Alagoas (NASCIMENTO, Emerson do; SANTANA, Luana)

atravessa o corpo, o espaço, o tempo, a geografia e o momento histórico. Um evento violento pode estabelecer um trauma sobre um indivíduo que pode transformar sua relação coma sociedade e, sequencialmente, uma série de outros eventos traumáticos podem ser iniciados.

Aqueles que vivem nos (ou através dos) destroços provocados pela violência, moldam suas vidas a partir da violência vivida pelos seus antepassados e também através da violência que experiência na sua vida. Não é, por conseguinte, o tempo que apaga ou cura a violência do racismo. Pelo contrário, quão distante o trauma da violência se implante na vida social, tão mais latente esteja do nosso cotidiano, isso não o faz menos importante ou influente sobre o nosso repertório social. Apenas aos privilegiados o esquecimento parece útil.

Se o tempo não cura, a intervenção do Estado e a organização das vítimas, em se tratando da violência sofrida, essa sim faz a diferença. A proposição e promoção de políticas reparatórias, que possam colocar em pé de igualdade de condições aqueles que tiveram suas vidas diretamente afetadas pela violência sofrida sobre os seus corpos ou de seus antepassados em detrimento da posição de privilégio daqueles que se beneficiam de sua condição ou da opressão histórica da população negra.

É preciso compreender que políticas reparatórias de caráter racial, por exemplo, não beneficiam negros em detrimento de brancos, mas, pelo contrário, oferecem condições mínimas de livre concorrência entre ambos. O trauma instaurado pela violência do racismo não pode, nem poderá, jamais, ser remediado. Sua intenção restringe-se a aliviar e atenuar os danos sofridos a partir do reconhecimento da responsabilidade pública e social, pelo trauma sofrido, e pelos danos físicos e psicológicos causados a uma comunidade (WEISSINGER \& MACK \& WATSON, 2017).

O segundo ingrediente importante desse processo diz respeito à sociedade civil. Primeiro a organização da comunidade, vítima direta dor racismo, aquela que recebe sobre seus corpos, a dor física e psicológica provocada pela prática do racismo. Falamos aqui, mais especificamente, do autocuidado, pelo reconhecimento do problema, pelo reconhecimento de que seu corpo internalizou estas violências imprimindo sobre si as marcas, por incontáveis vezes, letal da segregação e dos vícios perenes do racismo.

Depois, em se tratando da sociedade civil ainda, é importante que a população privilegiada também possa reconhecer que acolher e consentir que um território, uma 
Dossiê | Quando nenhum lugar é seguro: a violência contra corpos negros em Alagoas (NASCIMENTO, Emerson do; SANTANA, Luana)

rua, um bairro, uma cidade que não é segura para um cidadão negro, não é segura para todos. O reconhecimento de que o racismo não é um problema restrito às suas vítimas é também parte fundamental da abordagem desse problema. Não estamos falando aqui das afirmativas retóricas e oportunistas de que todas as vidas, pura e simplesmente, importam; mas sim a máxima de que algo que não é bom ou seguro para outro, não deve sê-lo para mais ninguém.

A violência vivenciada hoje, especialmente, pela juventude negra tem base histórica. A maneira pela qual o racismo enquanto fenômeno social não foi tratado ou resolvido na nossa trajetória, permitiu a configuração de um sistema desumano, promotor de inúmeras, e grandes injustiças que são revividas e ressignificadas a cada nova geração. A disfunção causada por esse histórico de violência é estruturalmente sustentada, portada e reencenada por cada rede familiar que experiencia os danos e os efeitos perturbadores do racismo.

Para além do abuso e da violência histórica e de sua rede de reprodução estrutural e da negligência por parte do Estado acerca do tema, temos ainda o outro lado dessa moeda que são as táticas de controle e contenção dessa comunidade por parte das estratégias de policiamento e encarceramento empreendidas pelo mesmo Estado que negligencia sua assistência e seu reconhecimento enquanto personas de direito (ALEXANDER, 2017). Na sua grande maioria as táticas de policiamento ostensivo e repressivo têm sido, diretamente, aplicadas sobre essa população que, não por acaso, constituem a maioria da população carcerária brasileira, mas são também os principais alvos das ocorrências de intervenção legal e as maiores vítimas de mortes violentas letais intencionais por todo o país.

\section{Segurança pública e negritude no brasil}

À despeito das ações afirmativas de combate à discriminação racial e das políticas de representatividade garantidas pelo Estado brasileiro para a população afrobrasileira desde 1988, de lá pra cá, poucos avanços foram registrados no campo da segurança pública. O baixo desenvolvimento de políticas orientadas à redução de riscos e reparação de danos para essa população no campo da segurança tem contribuído para 
Dossiê | Quando nenhum lugar é seguro: a violência contra corpos negros em Alagoas (NASCIMENTO, Emerson do; SANTANA, Luana)

composição de um quadro cada vez mais complexo quando tratamos dos crimes e das violências perpetradas nos nossos grandes centros urbanos.

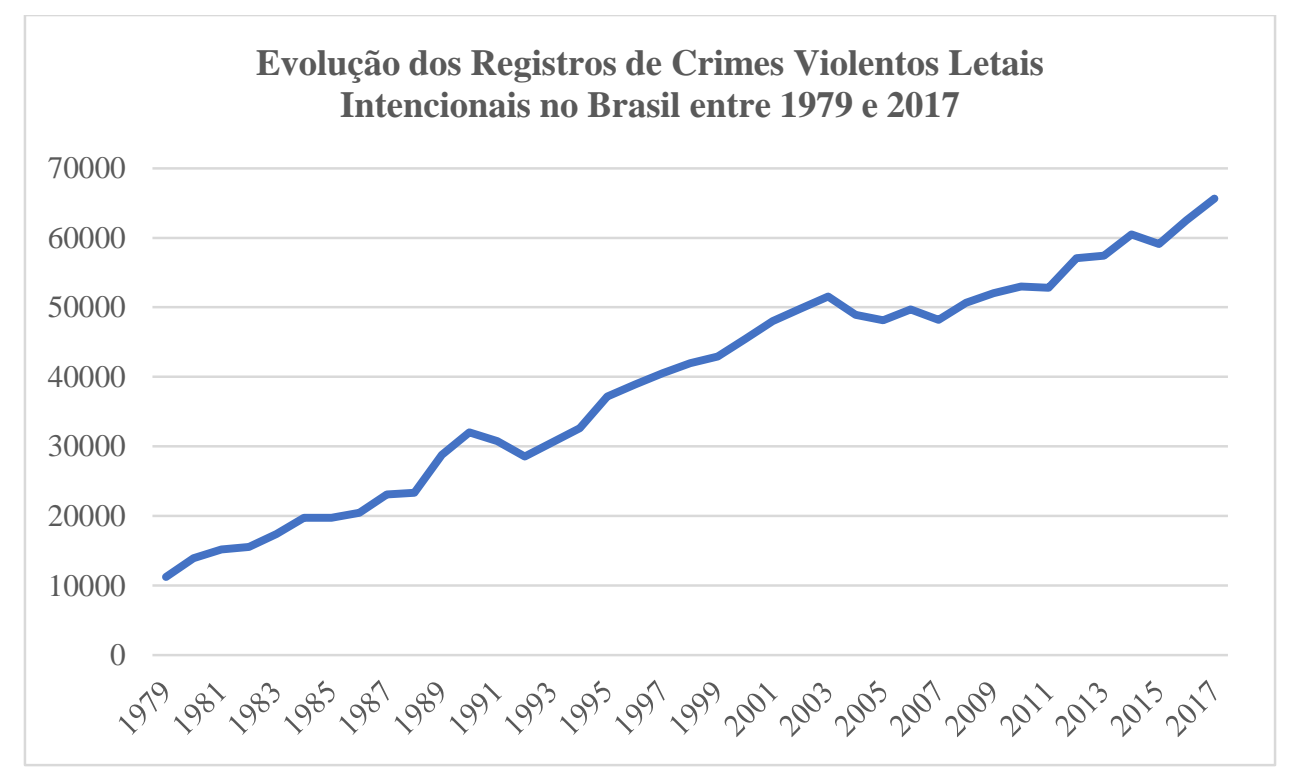

Fonte: SIM-MS; FBSP; IPEA.

Segundo dados do Instituto Brasileiro de Geografia e Estatística, a cada 3 assassinatos cometidos no Brasil, 2 são de jovens negros, com idades entre 15 e 24 anos. Se consideramos a parcela de $10 \%$ dos indivíduos com maiores chances de serem vítimas de assassinatos no Brasil, 78,9\% destes são negros ou pardos. Não estamos falando aqui de dados circunstanciais, mas de expressões de uma dinâmica que já se perpetua por décadas e que resiste em se alterar, mesmo com a expressiva redução da taxa nacional de homicídios.

A violência homicida é sem sombra de dúvidas, a maior expressão do racismo estrutural da sociedade brasileira (ALMEIDA, 2019). Ao longo da última década, a taxa de homicídios da população negra foi, pelo menos, permanentemente, o dobro da taxa de homicídios da população branca ou não negra. O ápice dessa apartação e da extrema condição de vulnerabilidade da comunidade negra à violência letal intencional no país tem recebido um relevo especial a partir do ano de 2017, quando a taxa nacional de homicídios começou a decrescer, mas essa redução tem sido experimentada somente entre a população não negra, tendo a taxa de homicídios da população negra, inclusive, aumentado. 
Dossiê | Quando nenhum lugar é seguro: a violência contra corpos negros em Alagoas (NASCIMENTO, Emerson do; SANTANA, Luana)

As hipóteses para a redução geral dos homicídios no país têm apontado, seja para a pacificação promovida pela trégua entre facções criminosas expandidas pelo território nacional, seja para os efeitos eficientes e positivos da modernização da segurança pública a partir de algumas experiências bem sucedidas, a grande maioria oriundas de iniciativa estadual, ou ainda, a transformação expressiva do nosso cenário demográfico, caracterizado por uma redução da população jovem. Essas hipóteses, isoladamente ou em conjunto, são interessantes para pensar a redução da violência homicida no país, mas dizem pouco por que essa redução não tem sido experimentada, literalmente, por todos.

No caso da concentração dos homicídios na população negra e até mesmo do seu acréscimo, quando comparado a taxa entre os brancos, fica patente que elementos estruturais estão em jogo. Estamos falando de políticas que não alcançam essa população, de indivíduos que habitam áreas e territórios subnormais, para os quais, muitas vezes, o Estado é inexistente ou para eles só lhes oferece sua face mais punitiva. A dimensão estruturante dessa realidade, não por acaso, se expressa com mais vigor nos estados do Norte e Nordeste, territórios de ocupação remota e de formação histórica escravista.

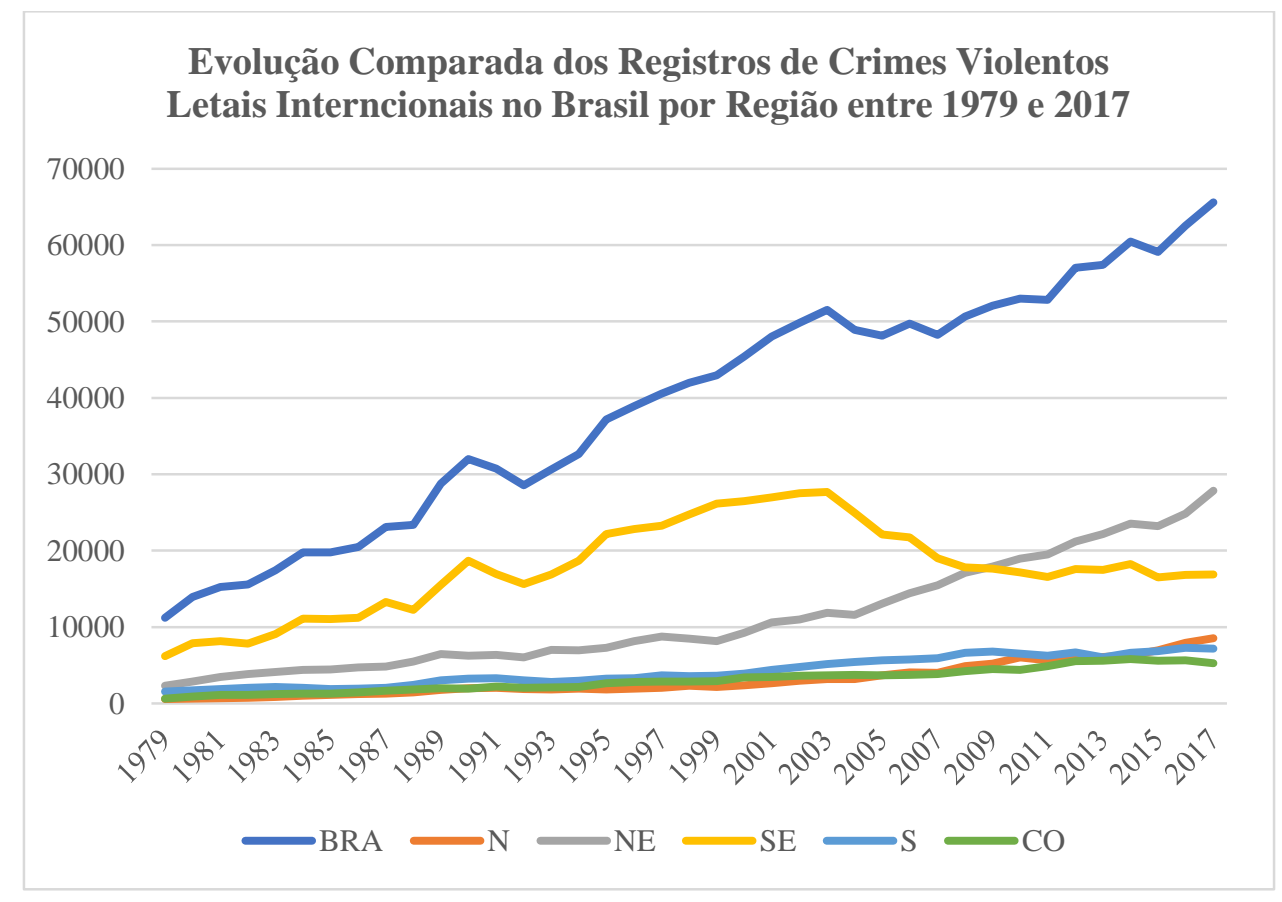

Fonte: SIM-MS; FBSP; IPEA. 
Dossiê | Quando nenhum lugar é seguro: a violência contra corpos negros em Alagoas (NASCIMENTO, Emerson do; SANTANA, Luana)

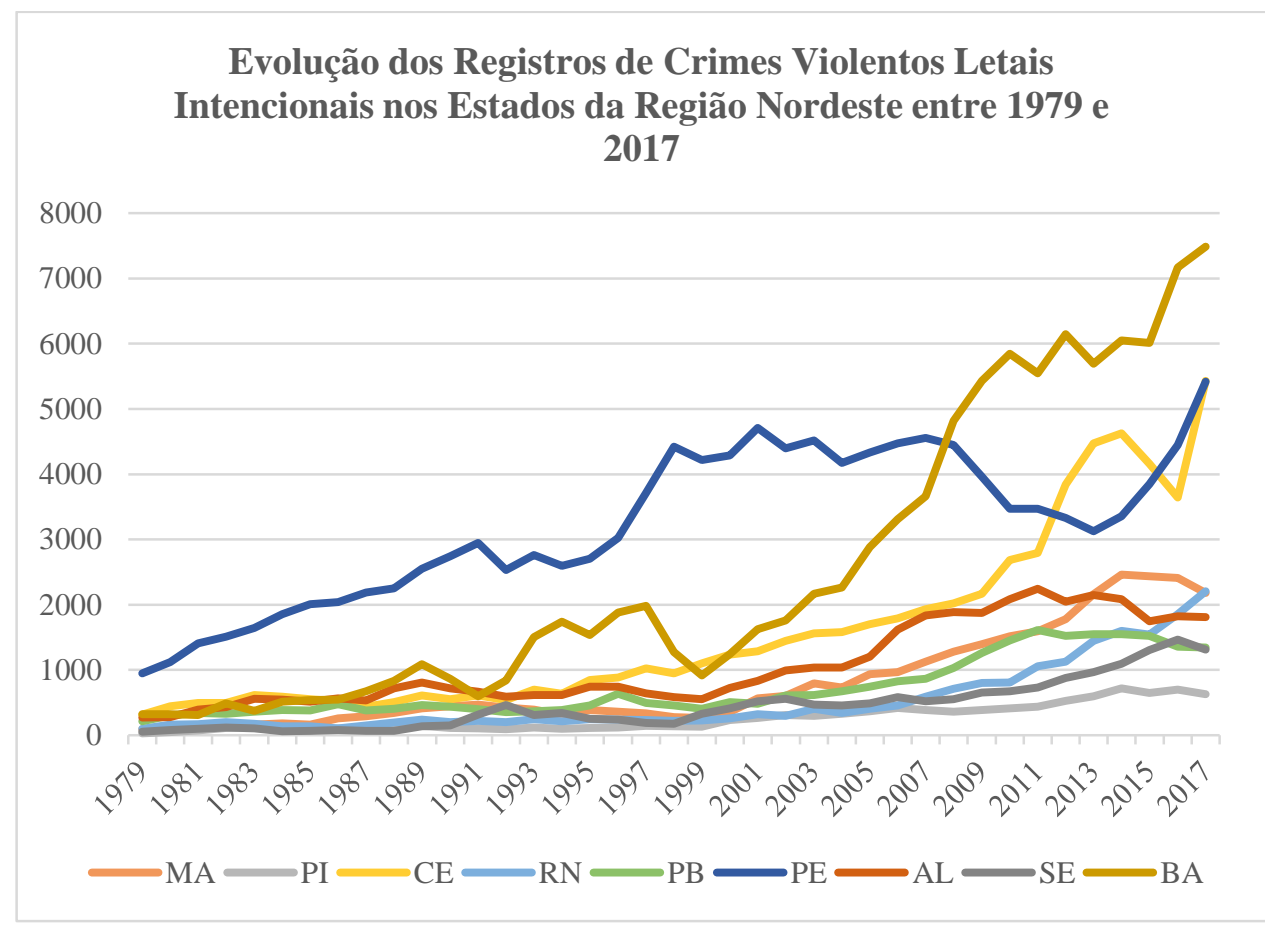

Fonte: SIM-MS; FBSP; IPEA.

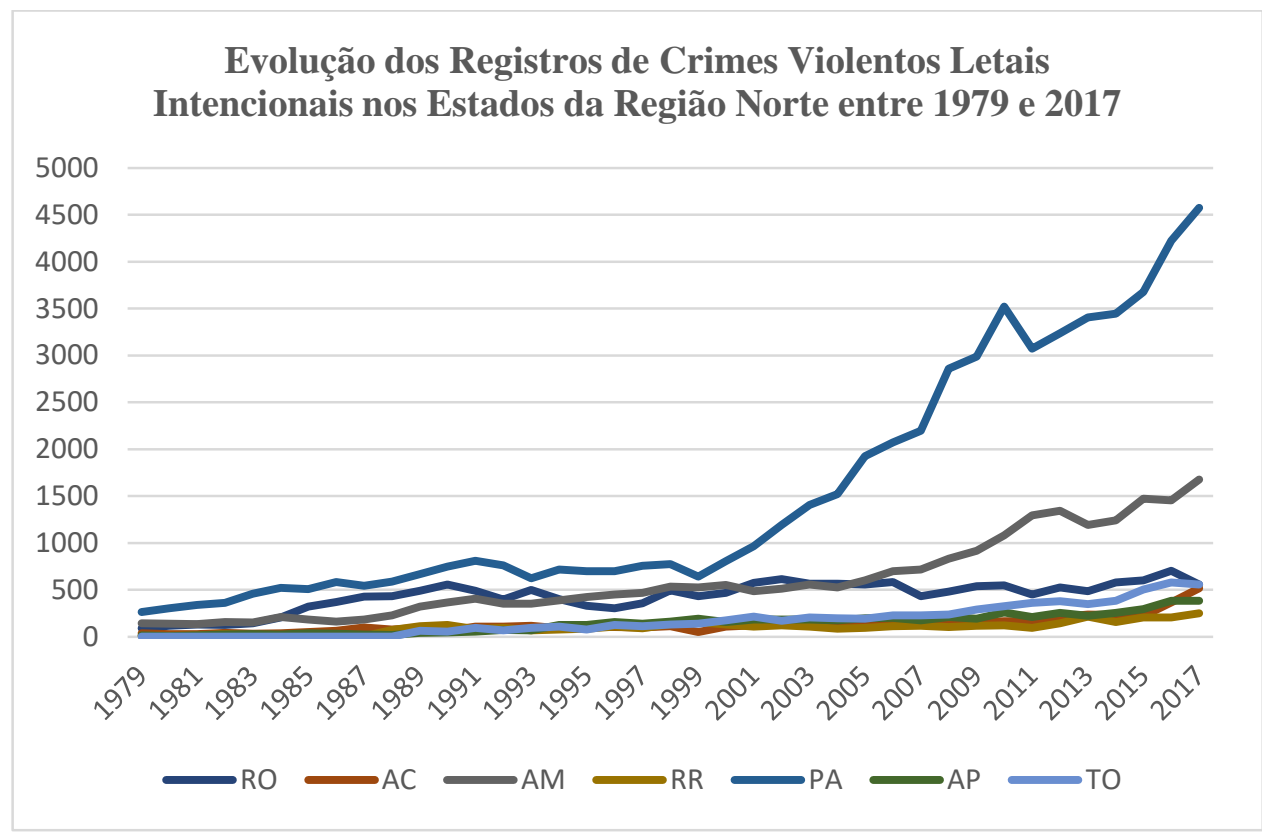

Fonte: SIM-MS; FBSP; IPEA.

Segundo dados do Fórum Brasileiro de Segurança Pública e do Sistema de Informação de Mortalidade do Ministério da Saúde para o ano de 2018, Roraima foi o estado brasileiro que apresentou a maior taxa de homicídios de negros de todo o país (são 87,5 homicídios por 100 mil habitantes). Depois de Roraima, segue o Rio Grande do 
Dossiê | Quando nenhum lugar é seguro: a violência contra corpos negros em Alagoas (NASCIMENTO, Emerson do; SANTANA, Luana)

Norte (71,6 por 100 mil habitantes), o Ceará (69,5 por 100 mil habitantes), Sergipe (59,4 por 100 mil habitantes) e Amapá (58,3 por 100 mil habitantes). Todos estados da região Norte e Nordeste, as quais, também têm experimentado, desde 2017, os maiores decréscimos proporcionais da taxa homicídios.

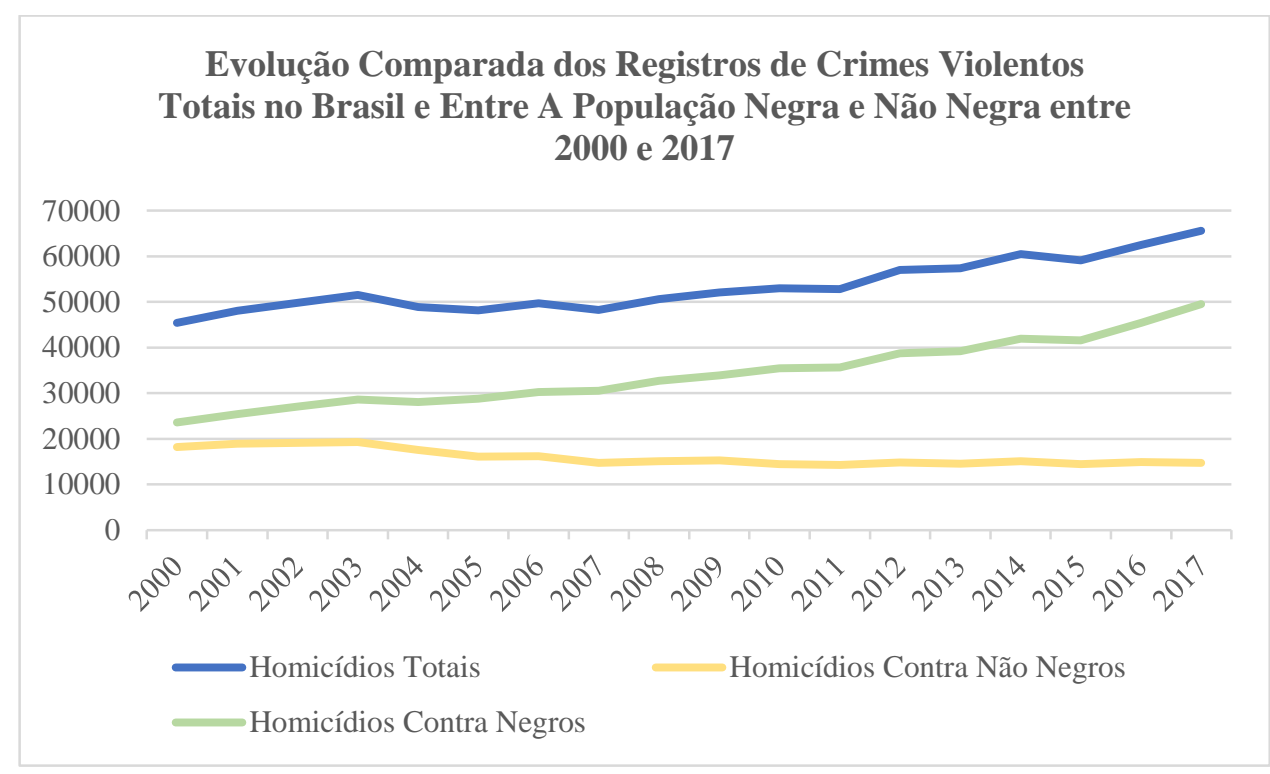

Fonte: SIM-MS; FBSP; IPEA.

Estamos tratando de uma situação que evolui para uma condição de insustentabilidade e imoral. Segundo dados do Atlas da Violência para 2018 ainda, por exemplo, de todos os homicídios registrados no país, $75,7 \%$ destes eram contra corpos negros, perfazendo uma taxa de 37,8 homicídios por 100 mil habitantes. Comparativamente, a taxa de homicídios de não negros para este mesmo ano foi de 13,9 homicídios por 100 mil habitantes. Portanto, a taxa de homicídios da população negra no país é 2,72 vezes maior que a da população branca e esses registros podem se tornar ainda mais escandalosos quando se compara esta mesma taxa a partir de cortes geracionais, pois a vulnerabilidade do jovem negro do sexo masculino consegue ser ainda maior. 
Dossiê | Quando nenhum lugar é seguro: a violência contra corpos negros em Alagoas (NASCIMENTO, Emerson do; SANTANA, Luana)

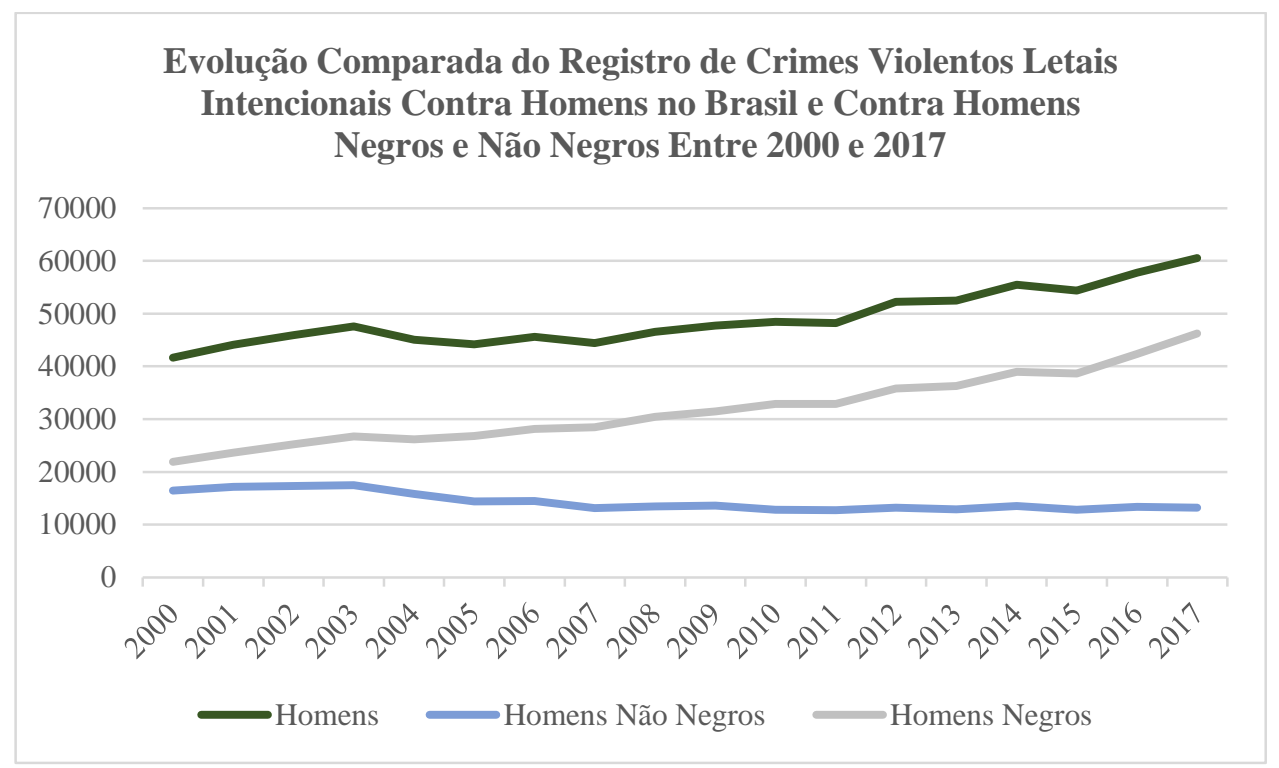

Fonte: SIM-MS; FBSP; IPEA.

Todavia, à despeito dos marcadores de gênero serem fundamentais no reconhecimento e mapeamento deste fenômeno, as mulheres negras não se encontram em condição melhor, pelo contrário. Da mesma forma que os homens, as mulheres negras são majoritariamente as principais vítimas da violência letal e representaram $68 \%$ do total de mulheres assassinadas no país em 2018. A taxa de homicídios de mulheres negras neste ano foi de 5,2 homicídios por 100 mil habitantes, praticamente o dobro da taxa de homicídios de mulheres não negras para o mesmo ano $(2,7$ homicídios por 100 mil habitantes). Esses dados revelam a dimensão perversa de um racismo que, apesar de negado, se materializa objetivamente nos corpos e na trajetória social dessa população. 


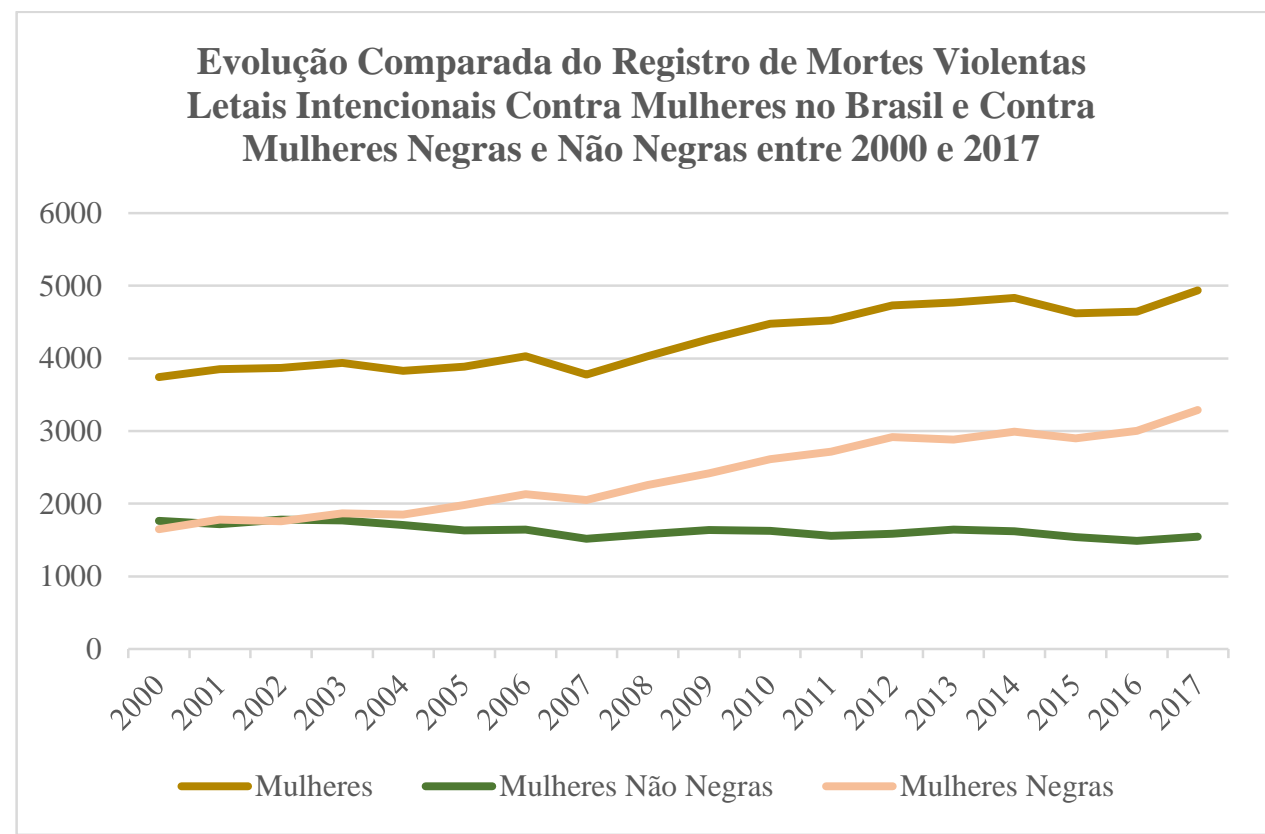

Fonte: SIM-MS; FBSP; IPEA.

A exposição dessas condições tem colocado a questão como um problema cada vez mais insustentável. Para aqueles que sempre se posicionaram contrários ao argumento de que há, de fato, um estrutura política de extermínio do corpo negro tem se tornado cada vez mais difícil dourar a pílula da democracia racial, posto que não há como discutir direitos civis, cidadania e democracia onde as condições de sobrevivência de uns é diametralmente oposta às condições de existência de outros. Ainda que não se vincule, de fato, um discurso deliberado de extermínio de um grupo étnico por parte do Estado, há em curso uma complexa marcha progressiva de eliminação e silenciamento destes indivíduos.

\section{A violência contra negros em Alagoas}

No estado de Alagoas, a situação da população negra faz-se ainda mais alarmante como talvez em nenhum outro estado da federação. Não por que Alagoas ostenta a maior taxa de homicídios de negros, mas por que o estado apresenta a maior diferença de vitimização entre negros e não negros de todo o país. Aqui, a chance de um negro ser vítima de violência letal intencional é 17 vezes maior do que para um branco ou não negro. Outros estados nordestinos também tem apontado para discrepâncias expressivas entre riscos de vitimização de negros e não negros, como 
Dossiê | Quando nenhum lugar é seguro: a violência contra corpos negros em Alagoas (NASCIMENTO, Emerson do; SANTANA, Luana)

Paraíba, Sergipe, Ceará e Rio Grande do Norte, contudo o caso de Alagoas merece atenção especial.

As dinâmicas de variação de vitimização entre negros e não negros em Alagoas, e que se concentram, prioritariamente na capital do estado, Maceió, têm chamado atenção para o fato de que a cidade que parece segura para uns, pode ser um inferno para uma parcela considerável da população. A representatividade dessa questão se torna ainda mais emblemática quando pensamos na sugestividade que o estado tem para o movimento negro brasileiro e para a própria representação da luta pela liberdade contra a escravidão na história da América Latina, pois estamos falando do território que abrigou o maior foco de resistência escrava da história do continente - o chamado Quilombo de Palmares.

Existente no Brasil por todo o período colonial, existiu por mais de um século, sendo destruído somente no final do século XVII por expedições portuguesas e holandesas. Hoje a história do quilombo e sua simbologia compõe um dos eixos de constituição de uma identidade diaspórica da negritude brasileira e alagoana. Talvez, não por acaso, a segregação exposta pelas diferenças de vitimização entre negros e não negros no estado fazem do caso alagoano uma situação que merece nossa atenção em detalhe.

De acordo com os dados do Sistema de Informação de Mortalidade do Ministério da Saúde para o último ano, Alagoas está na posição de 5a estado mais violento da federação quando se trata da taxa de homicídios cometidos contra jovens negros, apresentando 67,9 assassinatos para cada 100 mil habitantes, antecedido apenas por Rio Grande do Norte (87 por 100 mil habitantes), Ceará (75,6 por 100 mil habitantes), Pernambuco (73,2 por 100 mil habitantes) e Sergipe (68,8 por 100 mil habitantes) .

O cenário alagoano tem demonstrado que os ganhos recentes oriundos da promoção de políticas visando a redução da violência letal no estado (nos últimos 10 anos o estado tem promovido uma redução de até $27 \%$ da taxa de homicídios) não tem chegado a toda a população. Na verdade, poder-se-ia mesmo afirmar que essa política tem provocado um efeito perverso e não esperado - ela tem garantido mais segurança à população não negra, do que à população negra, a vítima por excelência do problema da violência. 
Dossiê | Quando nenhum lugar é seguro: a violência contra corpos negros em Alagoas (NASCIMENTO, Emerson do; SANTANA, Luana)

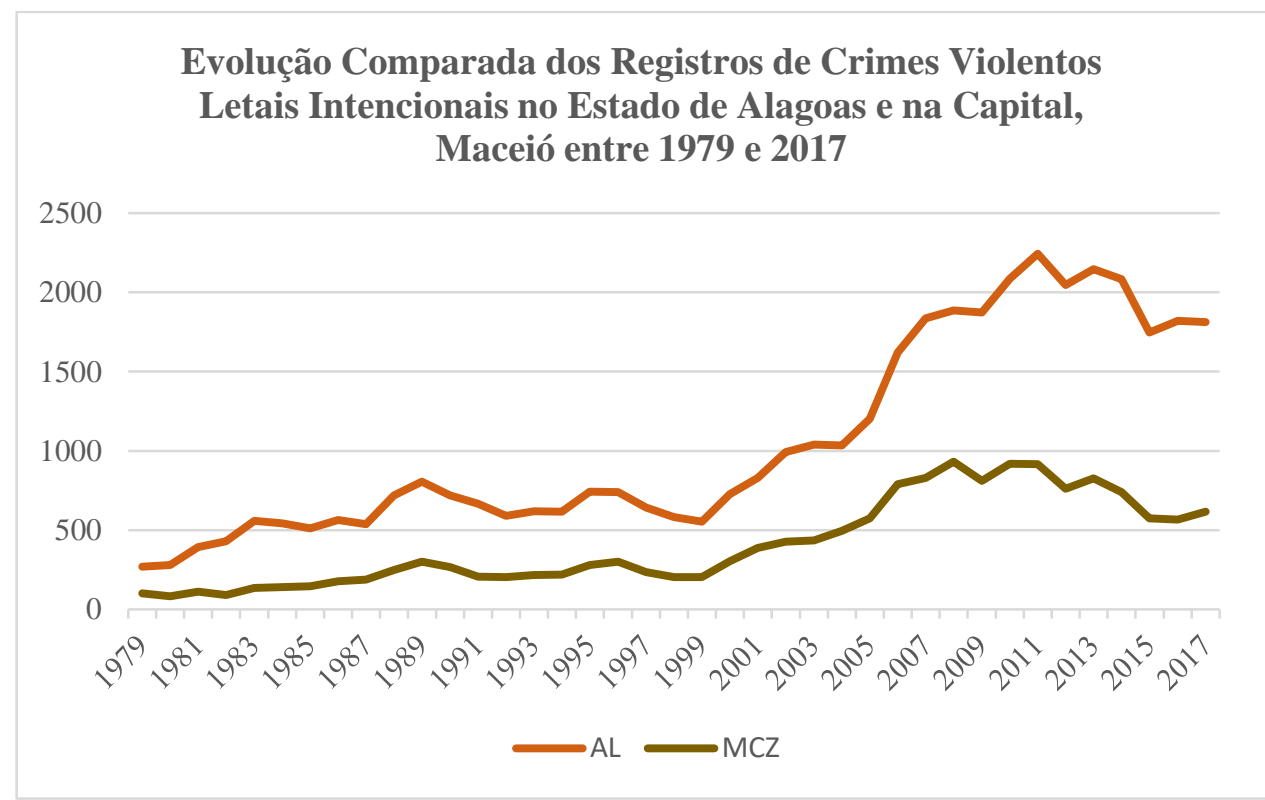

Fonte: SIM-MS; FBSP; IPEA; SSP-AL.

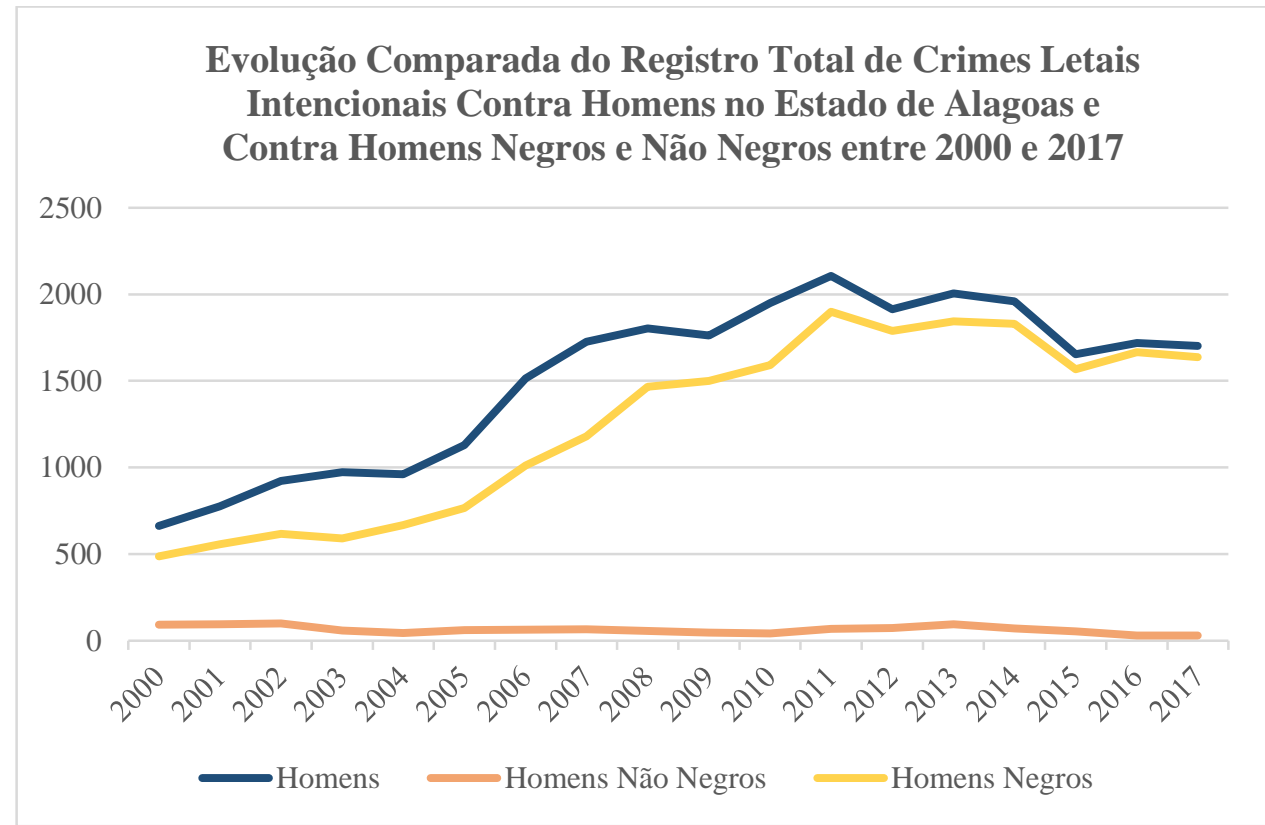

Fonte: SIM-MS; FBSP; IPEA; SSP-AL. 


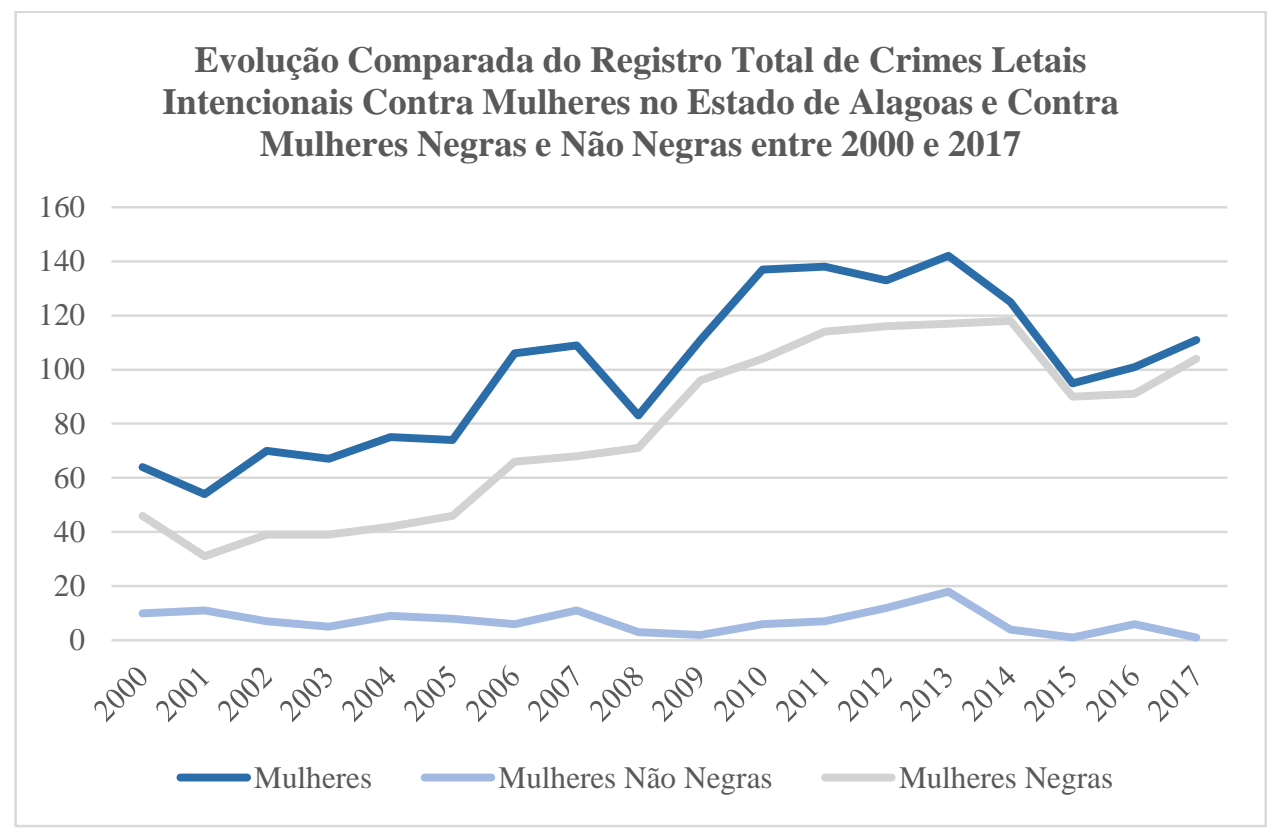

Fonte: SIM-MS; FBSP; IPEA; SSP-AL.

Os rumos dessa política têm apontado para um preço muito alto a se pagar, a saber: além das tragédias pessoais que cada morte traz, há que se destacar ainda a ampliação da promoção da segregação social e espacial da população afro-alagoana, vítima potencial dessa violência e habitante dos espaços mais vulneráveis da cidade de Maceió. Este quadro aponta para o quão perigosa a cidade se faz para a população negra, especialmente seus jovens e o quanto essa população carece hoje de políticas públicas que levem em conta marcadores étnico racionais, que sejam direcionadas à reparação dos danos já cometidos, mas também, direcionadas à redução dos riscos que vulnerabilizam essa população.

É notoriamente sabido, por parte da literatura especializada, que as condições de vulnerabilidade da população afro-brasileira estão diretamente relacionadas aos ciclos de desvantagens históricas a que cada geração está submetida e ao conjunto de obstáculos que esses indivíduos precisam enfrentar em suas trajetórias individuais limitando, inviabilizando ou dificultando o acesso destes, especialmente dos jovens negros e negras, à consagração de direitos e garantias fundamentais normatizados, porém, não efetivados.

Iniciativas visando o planejamento e a execução de intervenções estratégicas para a promoção de garantias e amparos políticos, jurídicos e sociais a essa população constitui, hoje, um dos pontos mais urgentes e emergentes da pauta da segurança 
Dossiê | Quando nenhum lugar é seguro: a violência contra corpos negros em Alagoas (NASCIMENTO, Emerson do; SANTANA, Luana)

pública brasileira e alagoana, em especial. É preciso contornar a omissão do poder público nesse aspecto, primeiro, reconhecendo o problema, assumindo a responsabilidade pela proteção da vida dessa população de forma objetiva através de ações visíveis, tangíveis para o cidadão, para o líder comunitário, para gestor público, para o policial, para os operadores do direito e da saúde.

O exemplo de outras redes e programas de prevenção em vias de institucionalização no país como a Rede de Prevenção à Violência contra Mulher, por exemplo, pode e deve ser levado em conta. É preciso compreender que programas de prevenção à violência contra grupos vulneráveis devem pautar-se, antes de mais nada, na elaboração de ações que priorizem a prevenção em detrimento do combate ao crime. E por que isso é tão importante? Por que as práticas rotineiras de policiamento ostensivo e combativo têm sido, potencialmente, um dos principais promotores também do punitivismo estatal; apresentando a uma população já vulnerável o peso da mão punitiva do Estado.

O que se espera hoje no campo da promoção da segurança para grupos vulneráveis é a superação do famigerado modelo de combate ao crime, em favor daquilo que tem despontado na literatura nacional e internacional como experimentação de sucesso - a combinação de intervenções amparadas por evidências com a promoção de políticas de ação integradas entre os agentes públicos com ênfase no respeito aos direitos da pessoa humana e no protagonismo social.

A guerra ao crime, empregada no Brasil desde os anos 1990 tem demonstrado de forma farta a sua insuficiência e sua insustentabilidade. Pautada em estratégias populistas e eleitoreiras, a ideia de que o crime é algo que se combate, perpetua a imagem de que a violência urbana ao invés de um problema social, seria, na verdade, caso de polícia. E, nesse sentido, infelizmente, à despeito de ações isoladas, as forças policiais brasileiras não se caracterizam como forças orientadas à prevenção do crime, muito pelo contrário.

A natureza militarizada das nossas forças policiais, reforçada pela sua estrutura hierarquizada de comandos e operações, mostra-se hoje pouco eficiente para essa função. Com isso, não queremos destacar que as forças policiais sejam desnecessárias, de forma alguma. Todavia, e isso é consensual entre os analistas da área, nossas polícias encontram-se hoje pouco aptas aos desafios dos nossos tempos, pelo menos no que diz 
Dossiê | Quando nenhum lugar é seguro: a violência contra corpos negros em Alagoas (NASCIMENTO, Emerson do; SANTANA, Luana)

respeito ao controle da violência nas cidades brasileiras. Menos preparadas ainda quando o assunto compreende as questões relacionadas à diversidade, seja ela étnica, racional, social ou até mesmo de orientação sexual.

Outro ponto importante, já destacado pela literatura especializada, mas pouco investido em termos práticos e de promoção de políticas é atacar também o problema silencioso da seletividade criminal da população negra. Embora tenhamos aqui um elemento menos tangível, no que diz respeito às suas causas, seus efeitos são bastante perceptíveis, sobretudo no corpo das vítimas, sobretudo a população negra. É preciso considerar que a prevenção à violência contra população negra deve, necessariamente, considerar também um conjunto de ações e intervenções que venha a promover uma transformação de sentido em relação à criminalização dessa população.

O objeto dessa seletividade é hoje visível no perfil étnico e social da nossa população carcerária, sobretudo dos nossos ditos presos provisórios, das vítimas da letalidade policial e dos registros de abuso mediante abordagens policiais. É compreendido pelas pesquisas mais recentes que esses elementos - a criminalização e a seletividade -, são elementos difíceis de erradicação, visto que se constituem a partir de cristalizações sociais da nossa história que imprimem desvantagens não somente de ordem material, mas também imateriais à população negra - associada recorrentemente ao crime, à marginalidade e ao desvio. Esses discursos de poder também precisam e devem ser atacados, sobretudo junto ao sistema de justiça (ADORNO, 1995). Para além da perpetuação do preconceito e do racismo, essa criminalização e essa seletividade penal são responsáveis diretos pela constituição da imagem dos jovens negros como inimigos que devem ser combatidos e eliminados por que vistos como "potencialmente" criminosos.

\section{Considerações finais}

A ideia de que os negros recém libertos seriam progressivamente incorporados, política, social e economicamente à sociedade brasileira esbarrou em limites de ordem histórica e estrutural que mesmo depois de tanto tempo, mantém sua atualidade emergente. De lá pra cá, o racismo mostrou sua capacidade de adaptação a variados contextos e formas de produção e reprodução do capital, que, cada vez mais, tem 
Dossiê | Quando nenhum lugar é seguro: a violência contra corpos negros em Alagoas (NASCIMENTO, Emerson do; SANTANA, Luana)

distanciado a população negra do efetivo exercício da sua cidadania e do cumprimento de garantais civis que são elementares a todos os indivíduos.

Embora população negra represente $54 \%$ da população brasileira segundo dados do IBGE para o ano de 2018, as condições de desigualdade que se apresentam para essa maioria pintam um quadro assombroso da condição social do negro no Brasil. Mesmo com os avanços conquistados a partir da Constituição de 1988, com o reconhecimento do crime de racismo e a afirmação dos princípios de reconhecimento político e social da afrodescendência a partir do credenciamento das comunidades ditas quilombolas, a condição de vulnerabilidade a que negros e negras são permanentemente expostos em nosso país sugerem que há em curso um processo progressivo de extermínio destas pessoas - os principais alvos da violência letal por aqui.

Nossa intenção nesse trabalho foi aprofundar o olhar sobre as práticas e dinâmicas dessa violência letal, alertando para o quanto esse fenômeno é histórico, sistemático e funcional, uma vez que contribui para a solidificação do racismo, a normalização da violência contra a população negra e o obscurecimento das condições de superação desse problema. Quando Fanon afirmou em 1964, que a desalienação do negro supõe uma tomada de consciência das realidades econômicas e sociais de onde se está inserido, ele talvez não pudesse conjecturar o quanto a abordagem do problema impõe também um giro epistemológico em relação às ações de Estado e à forma como o racismo precisa ser pensado e discutido enquanto fenômeno social que carece de atenção especial.

Tomar Alagoas como referência para pensar essas questões é também uma forma de aponta para a possibilidade emergente de experimentar a elaboração e implementação de políticas e programas de prevenção à violência contra a população negra que privilegie, além de recortes etário e étnico, a vulnerabilidade histórica e social desses grupos. A lógica da eliminação, de gestão da morte, para fazermos referência ao popularizado conceito de necropolítica de Mbembe (2018; 2012), chamam atenção para o quanto o Estado tem sido coparticipe pelo genocídio dessa população, seja através da promoção de políticas punitivistas e predatórias, seja, pura e simplesmente, através da sua omissão.

"Realizar a justiça", nesse sentido, conflui para o papel importante que as terras alagoanas sempre imprimiram para o movimento negro e para a população afro- 
Dossiê | Quando nenhum lugar é seguro: a violência contra corpos negros em Alagoas (NASCIMENTO, Emerson do; SANTANA, Luana)

brasileira como um todo, visto que Alagoas configurou-se, desde o período colonial, não somente como uma terra marcada e caracterizada pela violência, mas também como uma terra de resistência e embate contra a violência do mando e da escravidão. É nesse sentido ainda que o fenômeno não pode ser compreendido de forma fracionada, ainda que o tratamento científico do tema nos obrigue. É preciso que a violência genocida contra a população negra brasileira seja vista como parte um projeto contemporâneo maior que submete essa população a ciclos de desvantagens cuja exclusão é a principal tônica. É nossa missão na Universidade denunciar essa realidade, expor as engrenagens desse programa e ajudar a pensar de forma descolonizada a negritude e a gestão do racismo.

\section{Referências}

ALMEIDA, Sílvio. Racismo Estrutural. Série Feminismos Plurais. São Paulo: Pólen, 2019.

ADORNO, Sérgio. Discriminação Racial e Justiça Criminal em São Paulo. Novos Estudos, n.으 43, p. 45-63, nov. 1995.

ALEXANDER, Michelle. A Nova Segregação: Encarceramento em Massa na Era da Neutralidade Racial. São Paulo: Boitempo, 2017.

CHALHOUB, Sidney. Visões da Liberdade: Uma História das Últimas Décadas da Escravidão na Corte. São Paulo: Companhia das Letras, 2011.

CRENSHAW, Kimberle. On Interseccionality. Essential Writings. Nova York: New Press, 2017.

DAVIS, Angela. Mulheres, Raça e Classe. São Paulo: Boitempo, 2016.

FANON, Frantz. Em Defesa da Revolução Africana. Lisboa: Sá da Costa, 1980.

GORENDER, Jacob. O Escravismo Colonial. São Paulo: Expressão Popular; Perseu Abramo, 2016.

MBEMBE, Achille. Necropolítica. São Paulo: N-1, 2018.

Necropolítica: Uma Revisión Critica. In: MC GREGOR, H. C. Estética y

Violência: Necropolítica, Militarizacion y Vidas Lloradas. México: Universidade do México, 2012, p. $130-140$.

NASCIMENTO, Abdias do. O Genocídio do Negro Brasileiro: Processo de um Racismo Mascarado. São Paulo: Perspectiva, 2016.

RIBEIRO JÚNIOR, A. C. As Drogas, os Inimigos e a Necropolítica. Cadernos do CEAS, Salvador, n.o 238, p. 595-610, 2016.

VARGAS, J. C. A Diáspora Negra Como Genocídio: Brasil, Estados Unidos ou uma Geografia Supranacional da Morte e Suas Alternativas. Revista da ABPN, v. 1, n. 2, p. 31-65, jul./out. 2010.

WEISSINGER, Sandra E.; MACK, Dwayne A.; WATSON, Elwood. Violence Against Black Bodies: Un Intersectione Analysis of How Black Lives Continue to Matter. Nova York/Londres: Routledge. 